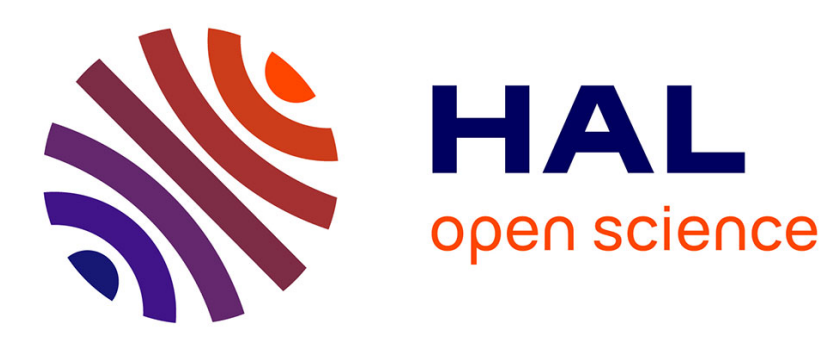

\title{
In-plane position and orientation measurement of a mobile target by digital holography
}

Miguel Vergara, Maxime Jacquot, Guillaume Laurent, Patrick Sandoz

\section{To cite this version:}

Miguel Vergara, Maxime Jacquot, Guillaume Laurent, Patrick Sandoz. In-plane position and orientation measurement of a mobile target by digital holography. Latin America Optics and Photonics Conference, Aug 2016, Medellin, Colombia. hal-02134426

\section{HAL Id: hal-02134426 \\ https://hal.science/hal-02134426}

Submitted on 20 May 2019

HAL is a multi-disciplinary open access archive for the deposit and dissemination of scientific research documents, whether they are published or not. The documents may come from teaching and research institutions in France or abroad, or from public or private research centers.
L'archive ouverte pluridisciplinaire HAL, est destinée au dépôt et à la diffusion de documents scientifiques de niveau recherche, publiés ou non, émanant des établissements d'enseignement et de recherche français ou étrangers, des laboratoires publics ou privés. 


\title{
In-plane position and orientation measurement of a mobile target by digital holography
}

\author{
Miguel Asmad Vergara ${ }^{\mathrm{a}, \mathrm{b}}$, Maxime Jacquot ${ }^{\mathrm{c}}$, Guillaume J. Laurent ${ }^{\mathrm{d}}$, Patrick Sandoz ${ }^{\mathrm{a}}$ \\ ${ }^{a}$ Department of Applied Mechanics, FEMTO-ST Institute, UMR CNRS 6174, University of Bourgogne Franche-Comté, Besançon, France. \\ ${ }^{b}$ Sección Física, Departamento de Ciencias, Pontificia Universidad Católica del Perú, Apartado 1761, Lima, Perú. \\ ${ }^{c}$ Optics Department, FEMTO-ST Institute, UMR CNRS6174, University of Bourgogne Franche-Comté, Besançon, France. \\ ${ }^{d}$ Automation and Micro-Mechatronics Systems Department, FEMTO-ST Institute, ENSMM, UMR CNRS 6174, University of Bourgogne Franche- \\ Comté, Besançon, France. \\ Authore-mail address: masmad@pucp.edu.pe
}

\begin{abstract}
A vision method based on digital holography allows the simultaneous measurement of the in-plane position and orientation of a moving object with sub-pixel resolution over large ranges. Digital holography provides a lensless image of a pseudo-periodic pattern imprinted onto a LCOS SLM.

OCIS codes : (090.1995) Digital holography, (100.0100) Image processing, (120.0120) Instrumentation, measurement, and metrology, (150.5670) Range finding
\end{abstract}

\section{Introduction}

To perform diverse complex tasks at the micro- and nano-scales requires high-performance position control devices [1]. The fulfilment of this need stimulates an active research domain, especially in relation with the development of MEMS and new kinds of compliant actuators. The six degrees of freedom (dof) have to be addressed but main available sensors measure only one or two dof. In this context, optical devices presents the advantage to be contactless with the possibility to address several dof in parallel [2]. This paper explores the capabilities of digital holography to perform in-plane position measurements. The main point aims to benefit from the ultra-large depth-of-focus permitted by this lensless technique to get free from usual trade-offs between magnification, field of observation and depth-of-focus associated to refractive vision techniques. Furthermore, we place a pseudo-periodic pattern (PPP) on the target that allows subpixel resolution as well as large displacement ranges. The position encoding used in the PPP is based on linear feedback shift registers (LFSR) as described in previous work [3].

The displacement of the mobile target equipped with the PPP is first simulated by means of a Spatial Light Modulator (SLM) to which are send various images of the PPP corresponding to different series of positions and orientations. We thus simulate the detection of displacements without the need of actuators for proof-of-principle purposes as well as for optimizing diverse parameters. Further experiments performed on an actually moving target are then presented.

\section{Digital Hologram recording and image restoration}

A sequence of images of the PPP is generated with a SLM display. We use a phase-only LCOS-SLM from Hamamatsu (Model X10468-01) with a $12 \times 16-\mathrm{mm}^{2}$ active area, optically addressed by a $600 \times 792$ pixel image and with a $20 \mu \mathrm{m}$ pixel pitch. The SLM generates pure phase patterns that can be converted into amplitude ones by means of additional linear polarizers. We calculate the wave diffracted by the object $\Psi_{0}$ from the SLM at the plane $\mathrm{z}=\mathrm{z}_{0}$ with the use of angular spectrum of plane wave approach [4]. We thus obtain the hologram of the PPP. The method to restore the image was previously implemented and is described in [3].

In this work the SLM is used as one of the interferometer mirrors as depicted in Fig. 1. The digital holography setup is based on a Michelson interferometer. The light source is a CW $10 \mathrm{~mW} \mathrm{HeNe}$ laser. The beam is collimated and linearly polarized. It is divided by a $25 \mathrm{~mm}$ beam-splitter cube (BS), so that $50 \%$ of the incident beam overfills the SLM area and the other $50 \%$ fills the mirror (M). The diffracted pseudo-periodic pattern $\Psi_{0}$ coming from the SLM and the reference plane wave $\Psi_{\mathrm{R}}$ reflected from the mirror are coherently superimposed on the camera, thus giving a digital hologram. It is imaged on an 8-bit Complementary Metal Oxide Semiconductor (CMOS) camera ( $\mu$ eye USB2UI 1480SE M with $2560 \times 1920$-pixel, and pixel size $2.2 \times 2.2 \mu \mathrm{m}^{2}$ ). A sequence of moving images of the PPP are displayed onto the SLM and we record the corresponding sequence of digital holograms.

Fig. 2 presents an image of the PPP for a particular in-plane position as send to the SLM as well as the resulting hologram obtained numerically. This numerically-generated hologram is used as a theoretical reference to which we 
can compare the experimental holograms obtained by using either the SLM or the actually moving target. This comparison is instructive on diverse experimental limitations, due for instance to noises or to effects of the large SLM pixel size.

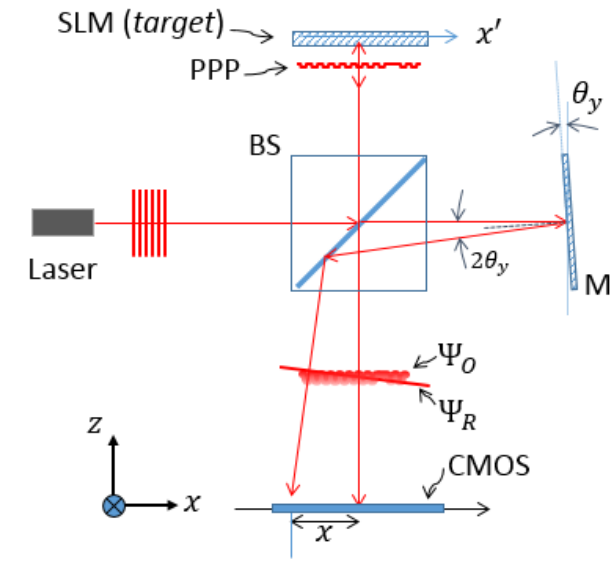

(a)

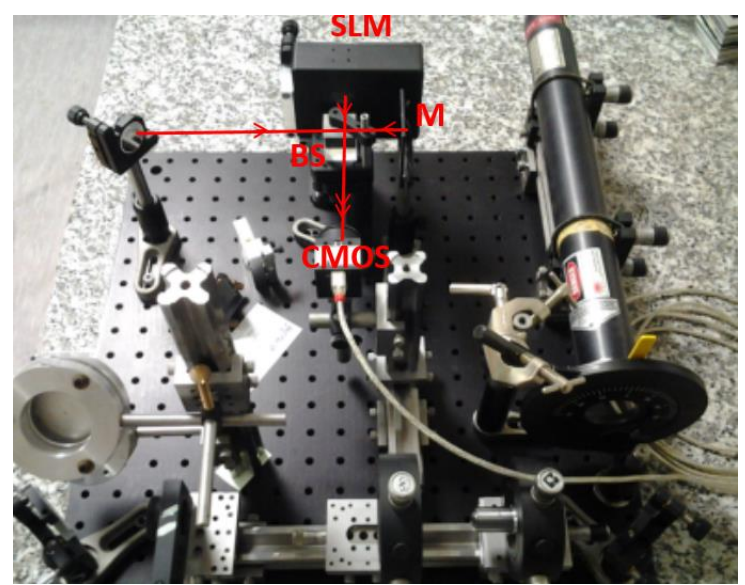

(b)

Fig. 1. (a) Schematic drawing of the experimental setup. CMOS: image sensor, BS: beam splitter, M: mirror, PPP: pseudo-periodic pattern wavefront reflected from SLM device. The incident beam is polarized linearly in order to display phase only modulation (b) Picture of the setup.

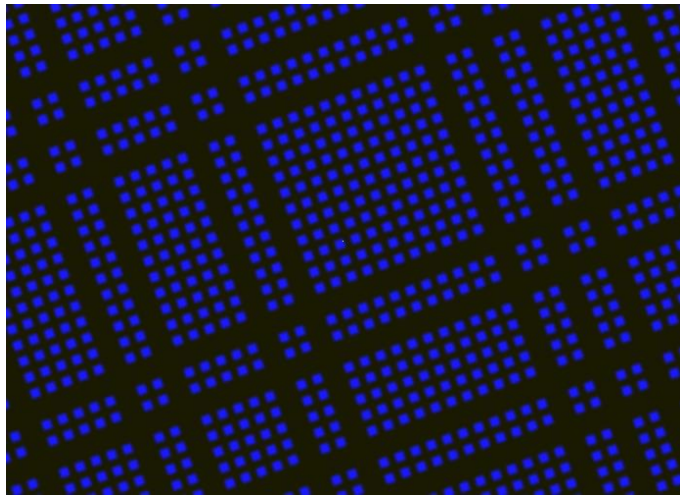

(a)

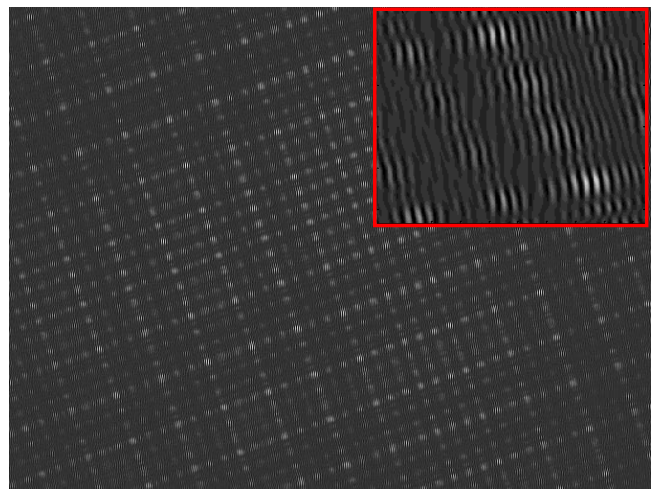

(b)

Fig.2. (a) Pseudo-periodic pattern, total size $5.6 \times 4.2 \mathrm{~mm}^{2}$. (b) Digital hologram of image (a) as numerically simulated. The image inserted is a zoom of the small part of the computed generated hologram and shows the modulated fringe carrier due to the tilt of the mirror M in Fig.2.

\section{Simulations and first experimental results}

Spatial light modulators (SLM) are devices that can modulate an incident laser beam either in amplitude or in phase but it is also possible to modulate both the amplitude and the phase. In Fig.3 (a) we show an experimental hologram as typically recorded experimentally with a PPP image displayed on the SLM modulated in amplitude only. The reconstructed PPP image is shown in Fig.3 (b).

In the Fig. 4(a), we show the reconstruction of an actual path combining X,Y, $\theta$ displacements, as reconstructed from a recorded sequence of digital holograms obtained with the SLM. The numerical reconstructed path (red cross + ) is compared with the position applied to the PPP (black dot and dash .-). We observe an excellent agreement and a sub-pixel resolution with a standard error along the lateral position below $0.2 \mu \mathrm{m}$ (pixel size: $2.2 \mu \mathrm{m}$ ). This performance has to be considered in regard to a range of displacement of the mobile target of $30 \mathrm{~mm}$. A similar level of performance is obtained for angular measurement as shown in Fig. 4 (b) for which a standard error below 0.14 sexagesimal degrees was obtained. 


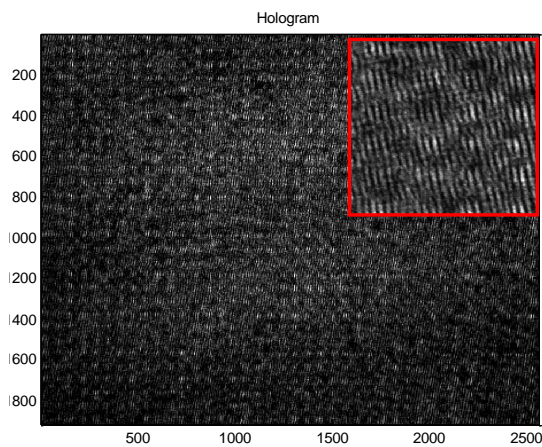

(a)

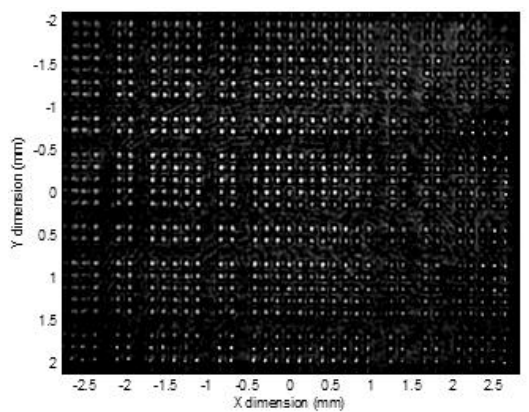

(b)

Fig.3. (a) An experimental hologram as recorded with the experimental setup. (b) Image of the PPP as numerically reconstructed from the hologram (a).

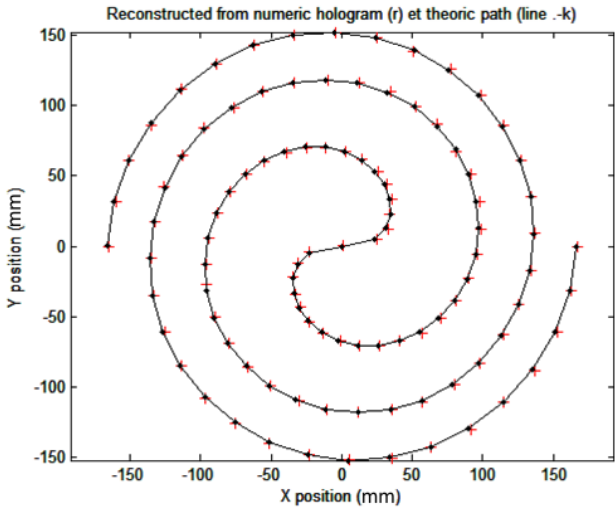

(a)

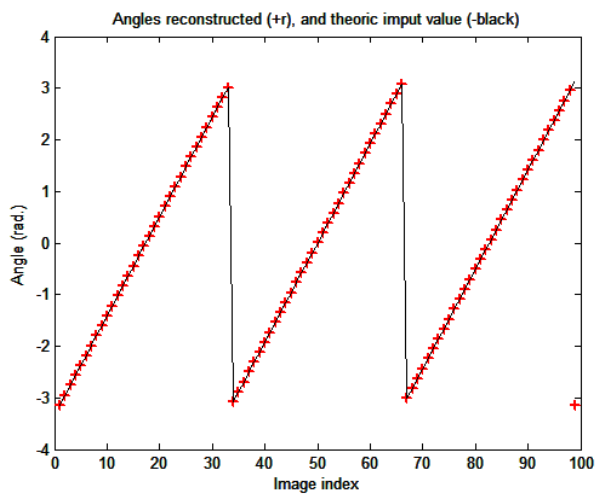

(b)

Fig. 4. (a) Reconstructed trajectory from the reconstructed images. (b): target path (dot and dash) and reconstructed path (red cross +). (b) Wrapped reconstructed (red cross +) and target (black line) angle of the pseudo-periodic pattern orientation.

Those results combining X,Y, $\theta$ displacements on the SLM device needs to be confirmed with a PPP placed on an actually moving target driven successively with a X,Y actuator and with a rotation motor. The same level of performance is expected with the SLM or an actual PPP. In all cases, the S/N obtained in the reconstructed PPP images allows a subpixel resolution in the reconstructed target position. This high level performances are associated with an acceptable range of displacement that is only limited by the actual PPP size without any kind of field-ofobservation constraint. Contrarily to refractive vision methods, digital holography is not subject to depth-of-focus limitations and the method can be applied on extra-large axial distances, up to $15 \mathrm{~cm}$ as we demonstrated experimentally.

\section{Acknowledgements}

We acknowledge Gilles Bourbon for clean room assistance and the RENATECH technological network and its FEMTO-ST facility MIMENTO. Miguel Asmad is supported by Student Grant Huiracocha Program-PUCP (Peru).

\section{References}

[1] N. Chaillet, S. Régnier (ed.), Microrobotics for micromanipulation. John Wiley \& Sons, 2013.

[2] P. Sandoz, J. Meneses, M. Suarez, et al. 3D localization of a labeled target by means of a stereo vision configuration with subvoxel resolution. Optics express, 2010, vol. 18, no 23, p. 24152-24162.

[3] P. Sandoz, M. Jacquot. Lensless vision system for in-plane positioning of a patterned plate with subpixel resolution. J. Opt. Soc. Am. A, Vol. 28, No, 12, pp. 2494-2500 (2011).

[4] Ting-Chung Poon and Jung-Ping Liu, Introduction to Modern Digital Holography with Matlab. Cambridge University Press, 2014, Chap. 4. 